\title{
Microstructure Effect of Heat Input on Ballistic Performance of Welded High Strength Armor Steel
}

\author{
Elson Renato Santos Souza ${ }^{1}\left(\right.$, Ricardo Pondé Weber ${ }^{2}\left[\right.$, Sergio Neves Monteiro ${ }^{2, *(1)}$ \\ and Suzane de Sant'Ana Oliveira ${ }^{3}$ \\ 1 Brazilian Army Assessment Center-CAEx, Rio de Janeiro 23020-240, Brazil; elsonqmb@yahoo.com.br \\ 2 Department of Materials Science, Military Institute of Engineering-IME, Rio de Janeiro 22290-270, Brazil; \\ rpweber@ime.eb.br \\ 3 Department of Inorganic Chemistry, Federal University of Rio de Janeiro-UFRJ, \\ Rio de Janeiro 21941-909, Brazil; susan.oliver@hotmail.com \\ * Correspondence: snevesmonteiro@gmail.com or sergio.neves@ime.eb.br
}

check for updates

Citation: Souza, E.R.S.; Weber, R.P.; Monteiro, S.N.; Oliveira, S.d.S.

Microstructure Effect of Heat Input on Ballistic Performance of Welded High Strength Armor Steel. Materials 2021, 14, 5789. https://doi.org/ $10.3390 / \mathrm{ma} 14195789$

Academic Editor: Daniel Casellas

Received: 7 August 2021

Accepted: 27 September 2021

Published: 3 October 2021

Publisher's Note: MDPI stays neutral with regard to jurisdictional claims in published maps and institutional affiliations.

Copyright: (c) 2021 by the authors. Licensee MDPI, Basel, Switzerland. This article is an open access article distributed under the terms and conditions of the Creative Commons Attribution (CC BY) license (https:// creativecommons.org/licenses/by/ $4.0 /)$.

\begin{abstract}
The effect of two different heat inputs, 1.2 and $0.8 \mathrm{~kJ} / \mathrm{mg}$, on the microstructure associated with a welded high hardness armor (HHA) steel was investigated by ballistic tests. A novel way of comparing the ballistic performance between fusion zone (FZ), heat-affected zone (HAZ), and base metal (BM) of the HHA joint plate was applied by using results of the limit velocity $V_{50}$. These results of $\mathrm{V}_{50}$ were combined with those of ballistic absorbed impact energy, microhardness, and Charpy and tensile strength revealing that the higher ballistic performance was attained for the lower heat input. Indeed, the lower heat input was associated with a superior performance of the HAZ, by reaching a $V_{50}$ projectile limit velocity of $668 \mathrm{~m} / \mathrm{s}$, as compared to $\mathrm{V}_{50}$ of $622 \mathrm{~m} / \mathrm{s}$ for higher heat input as well as to both FZ and BM, with 556 and $567 \mathrm{~m} / \mathrm{s}$, respectively. Another relevant result, which is for the first time disclosed, refers to the comparative lower microhardness of the HAZ (445 HV) vs. BM (503 HV), in spite of the HAZ superior ballistic performance. This apparent contradiction is attributed to the HAZ bainitic microstructure with a relatively greater toughness, which was found more determinant for the ballistic resistance than the harder microstructure of the BM tempered martensite.
\end{abstract}

Keywords: ballistic armor; low alloy high strength steel; shielded metal arc welding (SMAW); fusion zone (FZ) and heat affected zone (HAZ); microstructure; $\mathrm{V}_{50}$ ballistic resistance

\section{Introduction}

Steels used in ballistic armor need both a high hardness to stop an armor-piercing bullet by shattering its tip as well as enough toughness to prevent armor fragmentation after the projectile impact [1-4]. The way to simultaneously achieve these properties, which in principle are antagonists, is by combining a heat treatment, usually quench and temper (Q\&T), and adding alloying elements that increase the hardenability of the material [5-8]. In the case of high hardness steel for armor (HHA), the main alloying additives are chromium $(\mathrm{Cr})$, nickel $(\mathrm{Ni})$, and molybdenum (Mo). In the fabrication of combat vehicles, HHA are usually welded by shield metal arc welding (SMAW) $[9,10]$, flux core arc welding (FCAW) [5], gas metal arc welding (GMAW) [11,12], or laser-arc hybrid welding (LAHW) [13]. The welded joint, comprising the fusion zone (FZ) and heat affected zone (HAZ), has been considered over the years a relatively softer region, which should have lower ballistic resistance, in comparison to the base metal (BM). Indeed, in an earlier report, Wilson [14] stated that hardness is a major requirement for ballistic performance. Ade [15] as well as Reddy and Mohandas [16] corroborated hardness as a main factor in the ballistic qualification of armor steel weldment. In a general work on metallic armors, Crouch [17] emphasized the relevance of hardness on the ballistic performance of materials from aluminum to high strength steels. The special case of welded HHA is of common interest regarding ballistic protection. According to Ramana et al. [18], the harder the 
welded steel the better is its ballistic performance. Indeed, welded low alloy HHA are typically applied where weight reduction and projectile penetration resistance become key considerations [5].

However, other factors might also be relevant regarding the ballistic resistance of a low alloy HHA welded joint. The microstructure plays an important role and is associated with the mechanical properties [15]. While the BM consists of harder tempered martensite resulting from the Q\&T treatment, the relatively softer FZ and HAZ depend on the welding heat input. A higher heat input (HHI) was followed by fast cooling results in coarse-grained HAZ with predominantly martensite microstructure [18]. By contrast, Pramanick et al. [19] indicated that weld joint with lower heat input (LHI) show good ballistic performance. No specific microstructure was mentioned by the authors for the HAZ.

In addition to works focusing on microstructure, those on process conditions effects, such as different welding techniques [20]; thermal cycling [17]; filler [21]; welding consumables [22]; welded joint design [23]; protective weld coatings [24] and welding heat input $[16,25]$, have also been conducted. As above mentioned, heat input is a welding process parameter that might significantly affect the ballistic performance of Q\&T HHA. Indeed, Reddy and Mohandas [16] investigated the effect of welding heat input on the hardness and ballistic performance of a Q\&T high strength low alloy $(1.00 \mathrm{Cr}, 0.75 \mathrm{Mn}, 0.55 \mathrm{Si}$, $0.35 \mathrm{Mo}$, and $0.10 \mathrm{Zr}$ ) steel. They found that the width of the softened HAZ increases with the heat input. As such, a greater heat input was associated with wider and softer HAZ that promoted a poor ballistic performance. They also indicated that, for the investigated heat inputs, the microstructure of the HAZ was predominantly composed of martensite. Reddy and Mohandas [16], however, did not indicate the steel origin or supplier. Moreover, other information, such as the Q\&T steel tensile strength and bullet impact energy, was not disclosed. It was also missing the interpretation of the term "ballistic limit", used in the article [16] as an indication of ballistic performance. It is also worth mentioning that in a recent work Savic and Cabrilo [25] also investigated the effect of heat input on the ballistic performance of armor steel and found the HAZ of the LHI more prone to projectile penetration than that of the $\mathrm{HHI}$ using the criterion of no punch holes made upon three fired projectiles; the authors reported that the HHI weldment failed to meet this criterion. As such, the LHI was found to have a higher ballistic performance than the HHI, which was not resistant to $7.62 \times 51 \mathrm{~mm}$ projectile penetration [25]. The same ammunition is now used in the present work.

Based on the relevant conclusions of Reddy and Mohandas [14] as well as Savic and Cabrilo [25] and motivated by the need to complement some open questions, the present work investigated the effect of heat input on the ballistic behavior of a welded Q\&T high strength low alloy $(\mathrm{Cr}, \mathrm{Ni}, \mathrm{Mo}) \mathrm{HHA}$ steel. The following questions still need to be answered. Is the HAZ microstructure only martensitic for both high and low heat inputs? If so, how does one would explain a poor ballistic performance associated with high HHI? Moreover, in all investigated Q\&T HHA welded joints, both in terms of ballistic qualification [15] as well as effects of heat inputs [16,25], joint design [24], and microstructure [19], the ballistic performance was qualitatively estimated by the observed aspects of projectile impact resulting on either partial penetration or perforation. In the present work, for the first time, it is reported a quantitative ballistic performance by means of the standard $V_{50}$ projectile limit velocity. Microhardness and Charpy tests were carried out in two heat input conditions, HHI and LHI, and the microstructure was evaluated along the FZ, the HAZ, and the BM by scanning electron microscopy (SEM). Ballistic tests were performed in the FZ, HAZ, and BM by measuring the impact energy as well as the $V_{50}$ ballistic limit. The results of the two different heat inputs were compared between each other as well as with the $\mathrm{BM}$ to evaluate their influence on the ballistic performance of the relatively softer FZ and HAZ regions of the weld. 


\section{Materials and Methods}

\subsection{Materials}

The material used in this work, as the base metal (BM), is a high hardness armor (HHA) steel developed and manufactured according to the MIL-DTL-46100E standard [26] by the Brazilian Villares Metals together with USIMINAS steelmakers. The steel was provided as rolled $8 \mathrm{~mm}$ thick plates. A heat treatment of quenching and tempering (Q\&T) yielded a hardness of $480 \mathrm{HB}(\sim 513 \mathrm{HV})$. Table 1 presents the chemical composition of the investigated Q\&T HHA steel. The weld filler metal electrode was supplied by Rio War Arsenal.

Table 1. Chemical composition of investigated HHA (\%).

\begin{tabular}{cccccccccc}
\hline Elem & $\mathbf{C}$ & $\mathbf{M n}$ & $\mathbf{S i}$ & $\mathbf{N i}$ & $\mathbf{C r}$ & $\mathbf{M o}$ & $\mathbf{C u}$ & $\mathbf{T i}$ & $\mathbf{P}+\mathbf{S}$ \\
\hline$\%$ & 0.31 & 0.42 & 0.93 & 0.57 & 0.76 & 0.30 & 0.05 & 0.03 & 0.009 \\
\hline
\end{tabular}

\subsection{Welding Process}

Plates with dimensions of $500 \mathrm{~mm} \times 250 \mathrm{~mm} \times 8 \mathrm{~mm}$ of beveled Q\&T HHA steel were shield metal arc welded (SMAW) as per the US Army code [27] using a ferritic low hydrogen stick electrode as filler metal. Two distinct welding heat inputs, herein indicated as lower heat input (LHI) and higher heat input (HHI), were considered as the main technical variable in the present work.

The LHI was applied from an electrode with $2.5 \mathrm{~mm}$ in diameter operating with an electric current of $68.1 \mathrm{~A}$, voltage of $21 \mathrm{~V}$, and welding speed of $10.6 \mathrm{~cm} / \mathrm{min}$ generating a heat (energy) of $0.8 \mathrm{~kJ} / \mathrm{mm}$. While the HHI was applied from an electrode with $3.25 \mathrm{~mm}$ in diameter operating with an electrode current of $84.7 \mathrm{~A}$, voltage of $21 \mathrm{~V}$, and welding speed of $8.91 \mathrm{~cm} / \mathrm{min}$, which generated a heat of $1.2 \mathrm{~kJ} / \mathrm{mm}$. Figure 1 illustrates the typical weld joints, both top and root, of the Q\&T HHA steel plate for the two different conditions of LHI and HHI. In most cases welding was performed in the same direction for top and root passes, Figure $1 \mathrm{a}, \mathrm{b}$. In a few cases, reversed direction was applied in the weldment, Figure $1 c, d$, to verify its influence on the ballistic results.
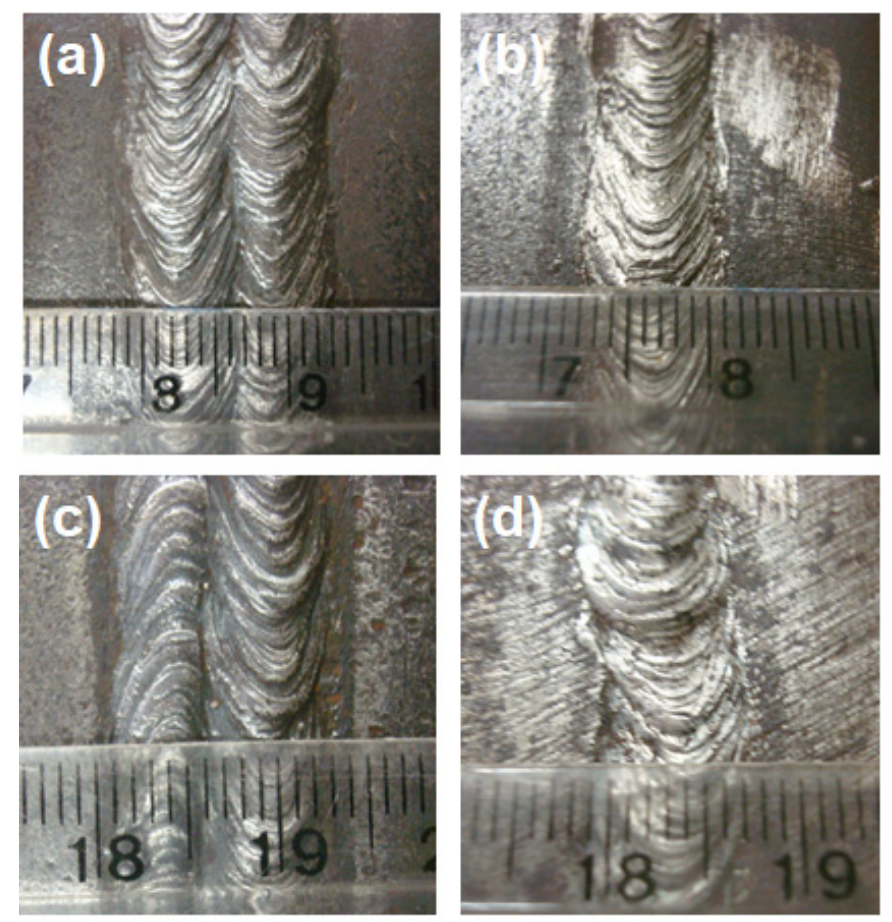

Figure 1. Typical Q\&T HHA steel welded joints. With higher heat input: (a) top and (b) root. With lower heat input: (c) top and (d) root. (Ruler small divisions in $\mathrm{mm}$ ). 


\subsection{Metallographic and Microstructure Analysis}

Metallographic analyses were performed on samples, cut by water jet, from both the FZ and HAZ in the welded Q\&T HHA steel plates. Macrostructural aspects were registered in a Zeiss stereoscope, model Stemi 2000-C and the microstructure analysis was performed by scanning electron microscopy (SEM) in a model Quanta FEG 250 FEI microscope (Schaumburg, IL, USA).

\subsection{Microhardness Measurements}

The Vickers microhardness profile along the weld joint was obtained for both LHI and HHI welding conditions, in a Micro Vickers Hardness model Indentec Zwick Roell digital tester (São Paulo, Campinas, Brazil) with an applied load of $500 \mathrm{~g}$, according to ASTM Standard [28]. Each microhardness value at a given point of the weld joint corresponds to the average of five close measurements.

\subsection{Charpy Impact}

Charpy impact tests were performed in a model PW30/15R Panambra, Brazil, using an impact pendulum hammer of $30 \mathrm{~J}$, to provide a preliminary evaluation of the Q\&T HHA steel HHI and LHI welded joint impact toughness. V-notched specimens were machined in both longitudinal and transversal rolling direction of steel plate for the BM. As for the weldment, seven transversal specimens with V notch in the HAZ, schematically illustrated in Figure 2 and processed with either HHI or LHI, were impact tested as per ASTM E2312c [29]. Due to the $8 \mathrm{~mm}$ thickness of the steel plate, non-standard sub-size dimensions of the Charpy specimen were machined as allowed by the norm.
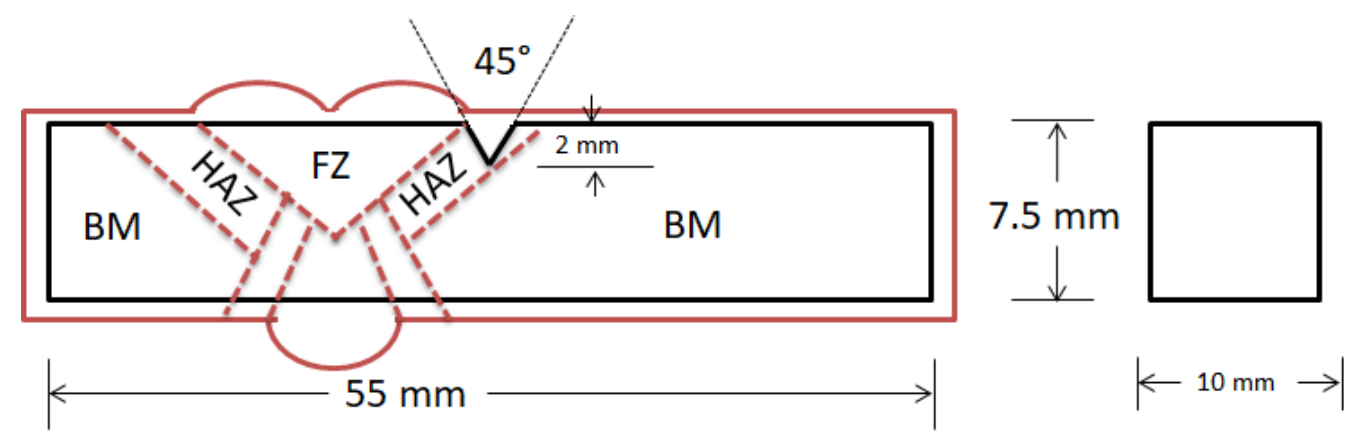

Figure 2. Schematic of V-notched Charpy specimen with sub-size dimensions as per ASTM E23-12c in black lines profile of the welded steel plate in red lines.

\subsection{Tensile Test}

Tensile tests were conducted in a 100-ton Contenco and Pavitest universal machine (Minas Gerais, São José da Lapa, Brazil) as per ASTM A370-12 [30] operating with crosshead speed of $5 \mathrm{~mm} / \mathrm{min}$ at room temperature. Standard flat tensile specimens were machined transversally to the steel plate rolling direction. BM specimens were cut outside the weldment. In specimens for HHI and LHI process conditions the complete weld joint was positioned at the center of the specimen gage length as shown in Figure 3. The specimen dimensions $(\mathrm{mm})$ are displayed in the schematic of Figure 3a while an actual tensile tested specimen in Figure $3 \mathrm{~b}$ revealed the beginning of rupture at the HAZ. Three specimens were tested for each condition corresponding to plain BM as well as HHI and LHI processed weldments.

\subsection{Ballistic Testing}

Ballistic tests were performed at the Brazilian Army Assessment Center (CAEx), Rio de Janeiro, according to the US Military standard [26]. A schematic illustration of the ballistic test is shown in Figure 4. Evaluation of ballistic performance was quantitatively 
done by the ballistic limit velocity $\mathrm{V}_{50}$, which provides a $50 \%$ probability of a projectile velocity to pierce a material.
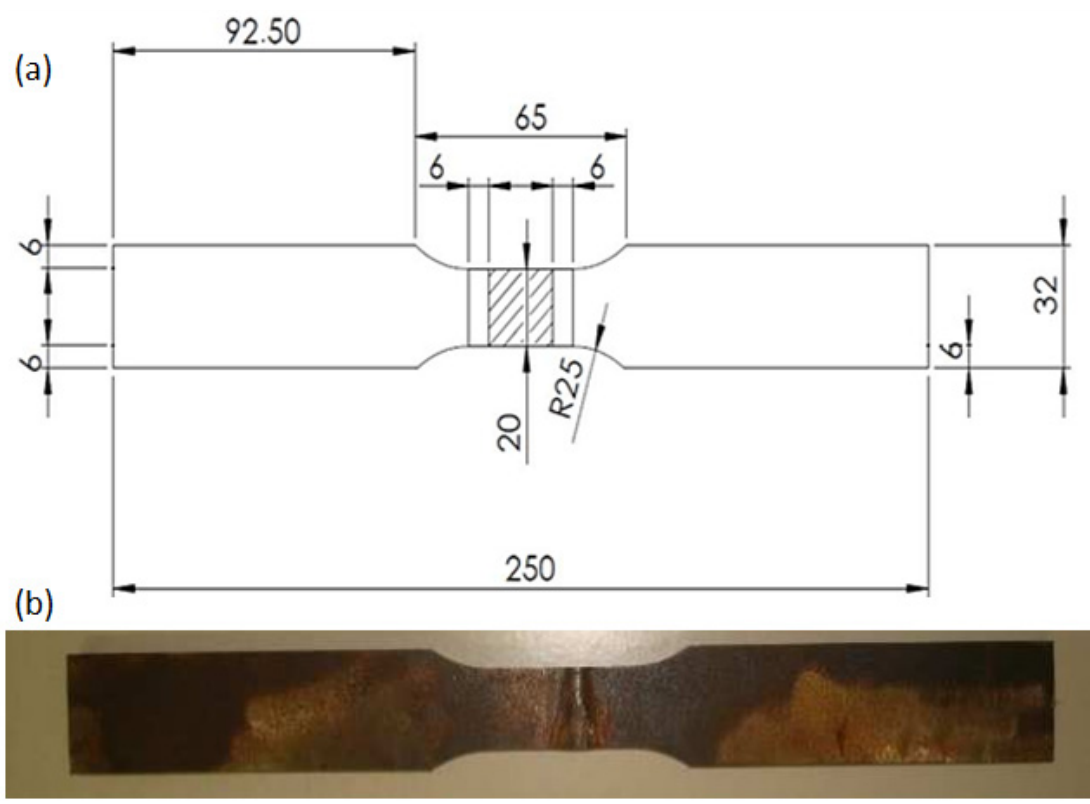

Figure 3. Tensile test specimens: (a) schematic with dimensions (mm), and (b) actually tested specimen with rupture beginning at the HAZ.

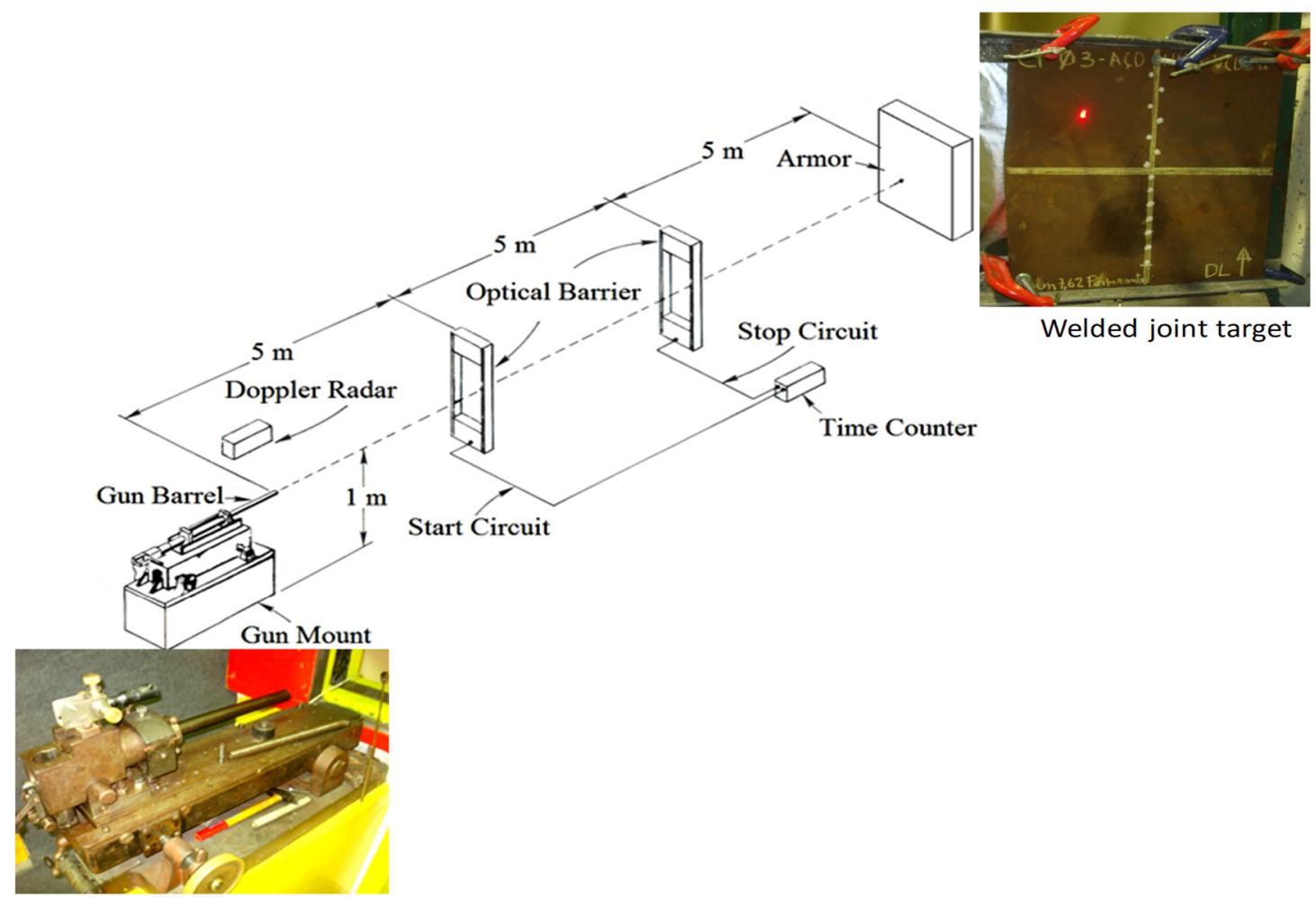

Figure 4. Schematic of ballistic test with actual gun barrel and welded joint target.

According to US Military Standard [31] and US Army code [27], the ballistic limit velocity $\mathrm{V}_{50}$ is a method for evaluating the ballistic resistance of an armor, determined by the average value of the projectile velocity of, either 2, 3, 4, or 5 through (complete) perforations and corresponding 2,3,4, or 5 partial penetrations. The test ammunition was a $7.62 \mathrm{~mm}$ full metal jacketed projectile loaded with different amounts of powder to obtain 
different impact velocities and allow the ballistic velocity limit to be evaluated. The bullet weighing $9.6 \mathrm{~g}$ was shot from a gun barrel to a welded target sample, as shown in Figure 4. A laser sight model B 290 indicated the exact point of bullet impact, exemplified by the red bright dot in the inserted target in Figure 4 . The target was placed $15 \mathrm{~m}$ away from the gun barrel and the bullet hit the sample at $90^{\circ}$ with respect to its surface. The bullet velocity was measured by a model SL-520P Weiber Doppler radar (Alleroed, Denmark), provided with WinDopp ${ }^{\circledR}$ software (Version 1.0) to process the radar raw data. The welded target sample was hit by the bullet with trajectory determined by the laser sight, at precisely the fusion zone (FZ) or the heat affected zone (HAZ), on welded joints fabricated with both LHI and HHI, as well as at the base metal (BM) as illustrated in Figure 5.
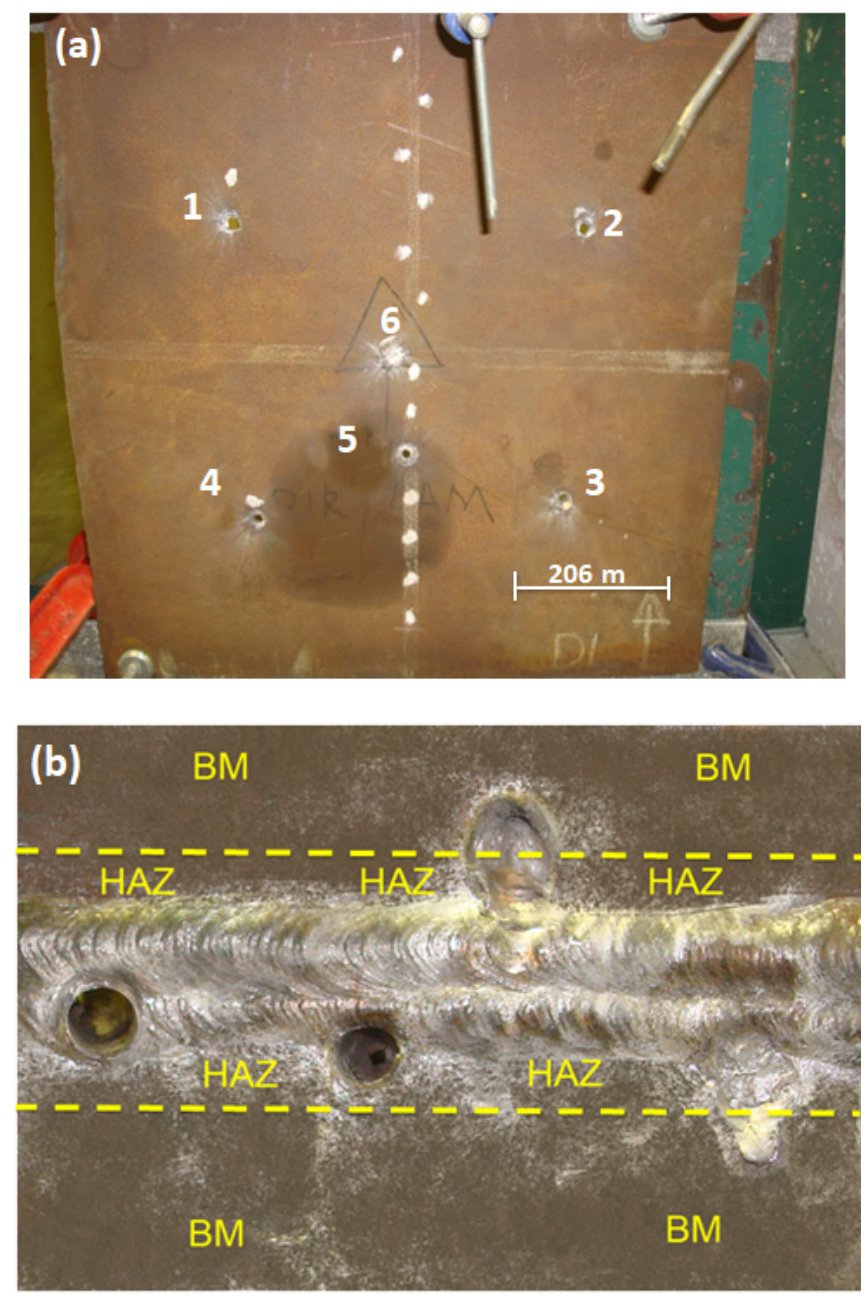

Figure 5. (a) Higher heat input Q\&T HHA shield metal arc welded joint after hit by $7.62 \mathrm{~mm}$ bullet shootings. (b) Actual plate and magnification view of weldment hits. Dashed yellow line as the limit of HAZ.

An actual HHA steel plate after several hits by $7.62 \mathrm{~mm}$ bullet shootings is shown in Figure $5 \mathrm{a}$. In this figure, shootings white-marked as 1 to 4 were performed only in the BM to assure proper ballistic properties. In particular, shooting numbers 5 and 6 are examples of weldment hits. Details with higher magnification of only weldment hits are shown in Figure $5 b$.

The projectile impact velocity $v_{i}$ against the HHA steel plate, Figure 4 , and its eventual residual velocity, $v_{r}$, leaving the plate in case of perforation are measured with precision from the Doppler radar image, as illustrated in Figure 6 from a previous work [32]. 


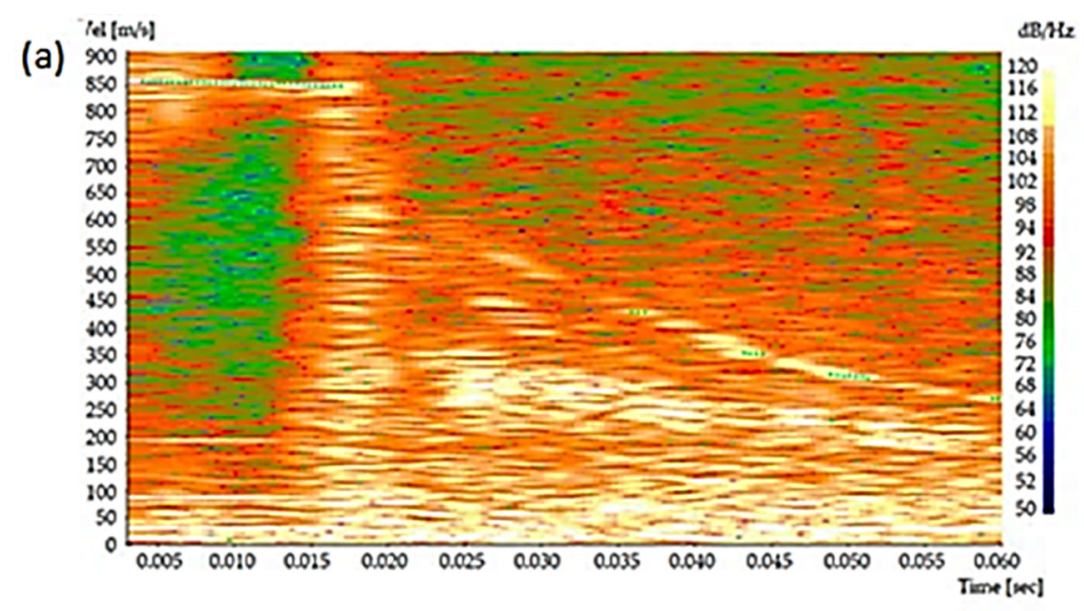

(b)

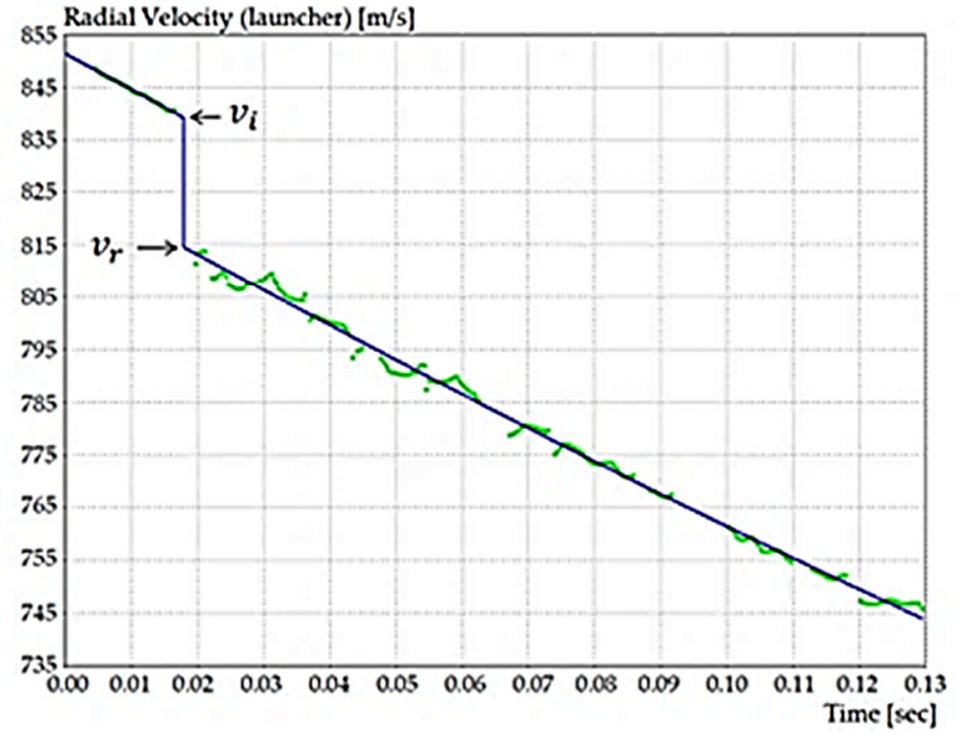

Figure 6. Impact and residual velocities measurement by Doppler radar: (a) actual computer recorded image (radar spectrum) of projectile velocity variation with time and (b) experimental points by FFT curve fitting. Reproduced with permission from [32].

The values of both $\mathrm{v}_{\mathrm{i}}$ and $\mathrm{v}_{\mathrm{r}}$ were calculated using the WinDopp ${ }^{\circledR}$ software, which correlates intensity with velocity by Fast Fourier Transform (FFT) to obtain the velocity versus time curve fitting, shown in Figure 6b.

Results from ballistic tests permit to measure the impact energy in addition to the ballistic limit $V_{50}$ for each welded target sample. The impact energy $E_{i}$ was measured by:

$$
\mathrm{E}_{\mathrm{i}}=\frac{1}{2} \mathrm{~m}\left(\mathrm{v}_{\mathrm{s}}-\mathrm{v}_{\mathrm{r}}\right)^{2}
$$

where $\mathrm{m}=9.6 \mathrm{~g}$ is the bullet mass and $\mathrm{v}_{\mathrm{s}}$ the bullet striking velocity at the impact against the target sample. In case of perforation, $\mathrm{v}_{\mathrm{r}}$ is the residual velocity of the bullet going out at the back of the target. The complete perforation was identified by visual observation of the passage of light in the projectile hole which is associated with the indication of a residual velocity by the Doppler radar.

\section{Results and Discussion}

\subsection{Characterization of Base Metal Steel}

The investigated Q\&T HHA steel used in the present work is a Brazilian army standard, close to the AISI 4340, with yield stress of $1390 \mathrm{MPa}$, ultimate strength of $1550 \mathrm{MPa}$ and total strain of $11 \%$. Microhardness measurements on this base metal (BM) steel per- 
formed about $20 \mathrm{~mm}$ away from the welded joint, disclosed an average value of $\sim 500 \mathrm{HV}$, with precise value depending on heat input, as further shown.

\subsection{Metallographic Analysis}

Figure 7 presents the macrostructure of the weld joints transversal section fabricated with either high heat input (HHI) or low heat input (LHI) conditions. In this figure it should be noted that the main macroscopic difference between the two conditions is related to the width of the heat-affected zone (HAZ). The HHI welded joint, Figure 7a, is comparatively wider $(\sim 5 \mathrm{~mm})$ than that $(\sim 3 \mathrm{~mm})$ of the LHI, Figure $7 \mathrm{~b}$. These results show the influence of the heat input on the widths of the distinct HAZ regions, in which a greater heat input leads to a wider HAZ zone, corroborating the results of Reddy and Mohandas [16].
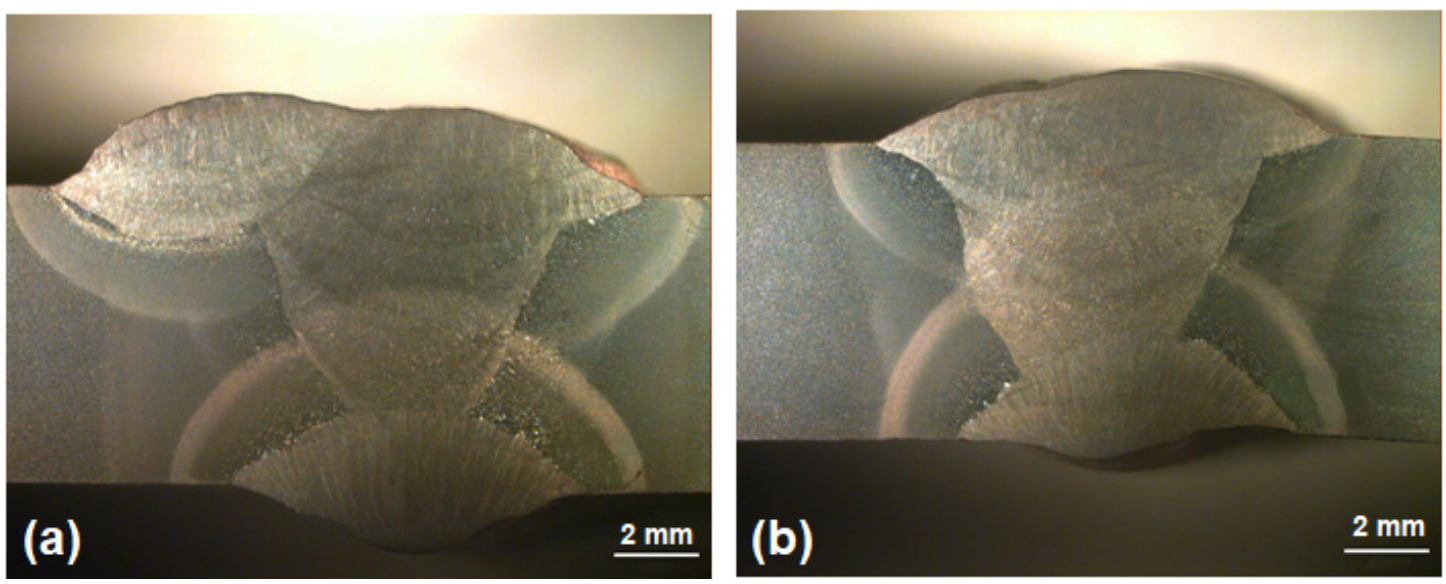

Figure 7. Macroscopic transversal section of welded steel: (a) with higher heat input; (b) with lower heat input.

Figure 8 shows by SEM the typical microstructure of the BM corresponding to the as-received Q\&T HHA steel. It is noteworthy in this figure that, as expected [22], the BM is mostly composed of tempered acicular martensite with evidence of martensite laths, indicated by arrows. Similar microstructure was also reported [5] for the BM of a Q\&T high strength low alloy steel welded joint, which was analyzed by optical microscopy (OM) as well as SEM and transmission electron microscopy (TEM). The identification of martensite laths within the acicular martensite was made based on visually similar pictures shown by Magudeeswaran et al. [5].

Figures 9 and 10 display by SEM the typical microstructures of (a) the fusion zone (FZ) and (b) the heat-affected zone (HAZ) of the Q\&T HHA steel welded with HHI and LHI conditions, respectively. The FZ microstructures, on both conditions, consist predominantly of polygonal ferrite as seen in Figures 9a and 10a. This is similar to the OM, SEM, and TEM results reported by Magudeeswaran et al. [5]. However, the LHI condition promotes comparatively smaller grain size $(\sim 15 \mu \mathrm{m})$ than the HHI $(\sim 30 \mu \mathrm{m})$ condition. These FZ microstructures are certainly softer than that of the BM owing to the greater grain size promoted by the HHI condition, as shown in Figure 9a.

The HAZ presents evidence of martensite laths and bainite needles that were identified in Figures $9 \mathrm{~b}$ and $10 \mathrm{~b}$. In particular, Figure $9 \mathrm{~b}$ reveals the boundary of the coarsened grains of the austenite formed above AC3 temperature before the quenching heat treatment. The grain size, on both heat input conditions, Figures $9 \mathrm{~b}$ and $10 \mathrm{~b}$, varied with the distance from the FZ/HAZ interface, revealing that the closer to the interface, the larger the grains. The HAZ microstructure in Figure $9 \mathrm{~b}$ for the HHI condition is composed of acicular tempered martensite and some bainite needles. The HAZ microstructure in Figure 10b for the LHI condition is composed basically of some tempered martensite laths, like those presented in the HHI condition, Figure $9 \mathrm{~b}$, and some acicular ferrite with predominance of bainite needles, pointed by arrows. 


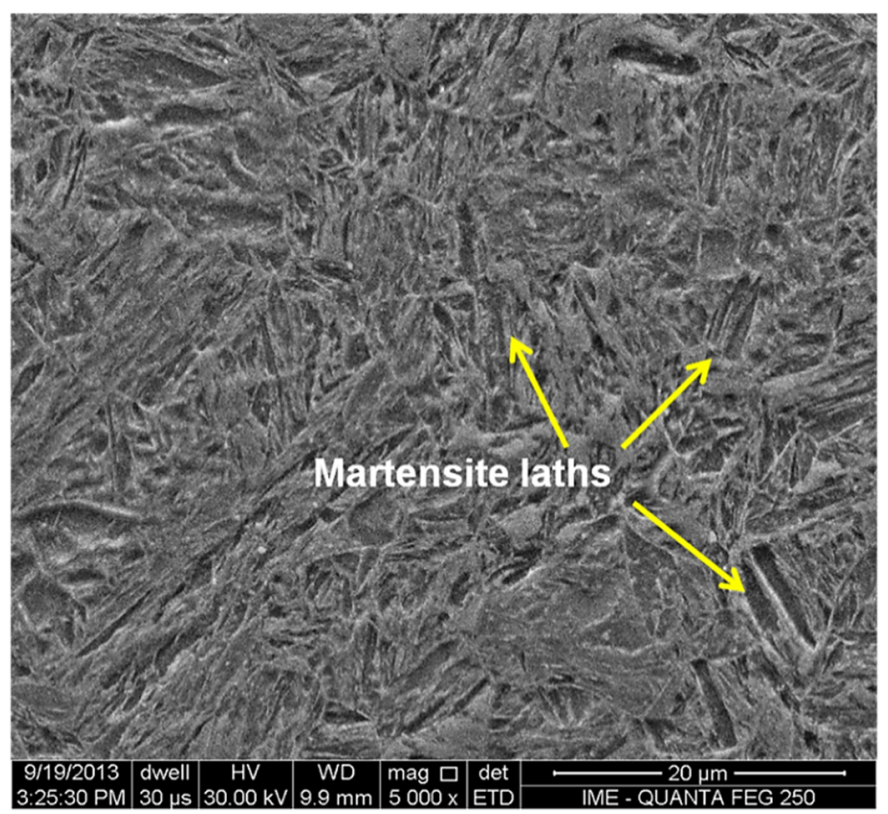

Figure 8. SEM micrograph of the base metal.
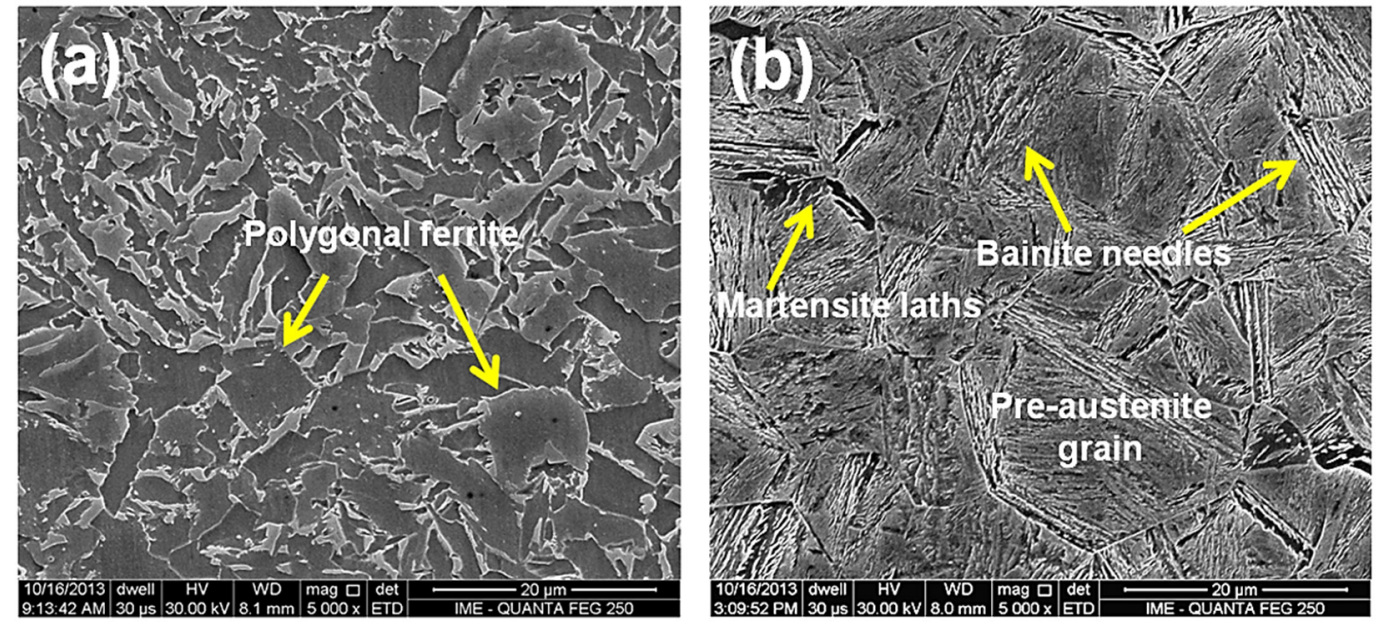

Figure 9. SEM micrographs of the higher heat input welded joint, in the regions (a) FZ and (b) HAZ.
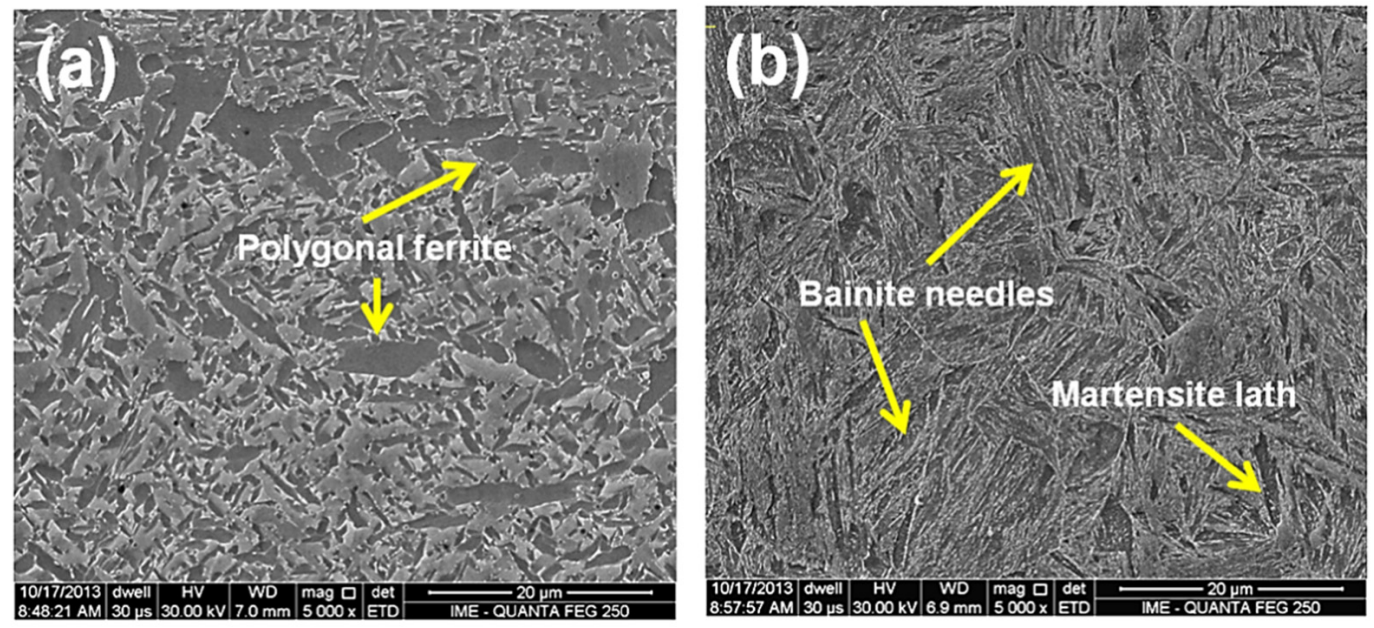

Figure 10. SEM micrographs of the lower heat input welded joint, in the regions (a) FZ and (b) HAZ. 
The existence of bainite needles was also reported by SEM and TEM in the HAZ of a similar Q\&T HHA steel (close to AISI 4340) studied by Pramanick et al. [19]. In the present work, the identification of bainite in Figures 9 and 10 was based on the pictures reported and discussed by those authors. The authors concluded that among the different microstructural constituents, lower bainite with maximum toughness could be considered as the most desirable microstructure for an armor steel weld metal. Due to the importance of these constituents, Unfried et al. [33] showed a modeling approach disclosing the microstructure evolution, based on both Reddy and Mohandas [16] and Reddy et al. [20] research works.

Preliminary EDS results obtained from the SEM system failed to reveal significant difference in the distinct phases, Figures 9 and 10, as compared with the steel composition in Table 1.

\subsection{Vickers Microhardness Profile}

Table 2 presents the microhardness values in each region, indicated by numbered white points in the etched transversal section, Figure 11, according to the graphical profile shown in Figure 12. The microhardness values in this table reveal that the LHI promoted the greatest hardness in the FZ and BM.

Table 2. Microhardness at weldment regions, according to Figure 8.

\begin{tabular}{cccc}
\hline Weldment & Region & $\begin{array}{c}\text { High Heat Input } \\
\text { (HV) }\end{array}$ & $\begin{array}{c}\text { Low Heat Input } \\
\text { (HV) }\end{array}$ \\
\hline FZ only & 1 & $222 \pm 4.9$ & $246 \pm 2.5$ \\
& 2 & $219 \pm 2.8$ & $259 \pm 19.0$ \\
\hline FZ near HAZ & 3 & $384 \pm 86.1$ & $275 \pm 3.5$ \\
\hline HAZ near FZ & 4 & $430 \pm 20.3$ & $349 \pm 131.5$ \\
\hline HAZ only & 5 & $375 \pm 33.6$ & $445 \pm 12.7$ \\
\hline HAZ near BM & 6 & $414 \pm 6.5$ & $429 \pm 14.2$ \\
\hline BM near HAZ & 7 & $437 \pm 13.8$ & $446 \pm 10.5$ \\
\hline BM only & 8 & $481 \pm 26.8$ & 24.3 \\
\hline
\end{tabular}
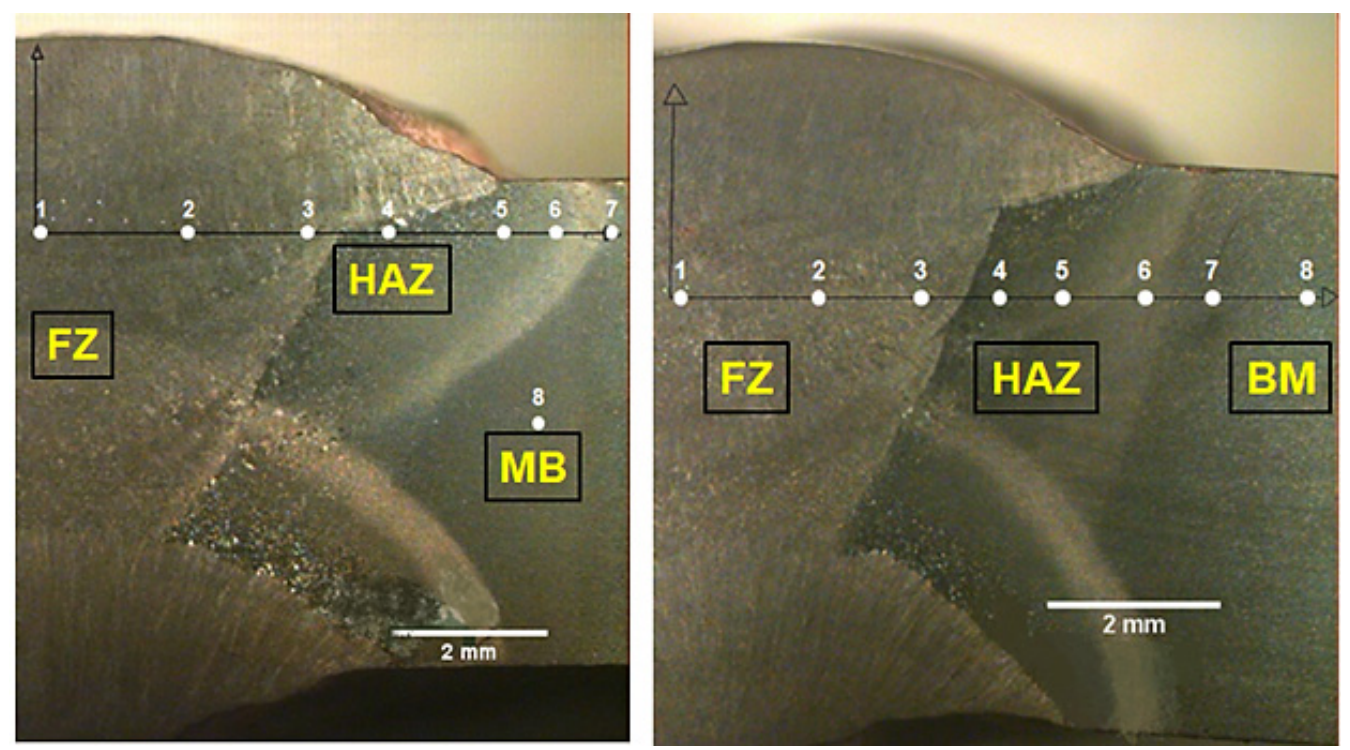

Figure 11. Microhardness numbered points (white) in the etched transversal section of the welded HHA steel, from the center of FZ to BM, across the HAZ. Minimum of 5 measurements per point. 


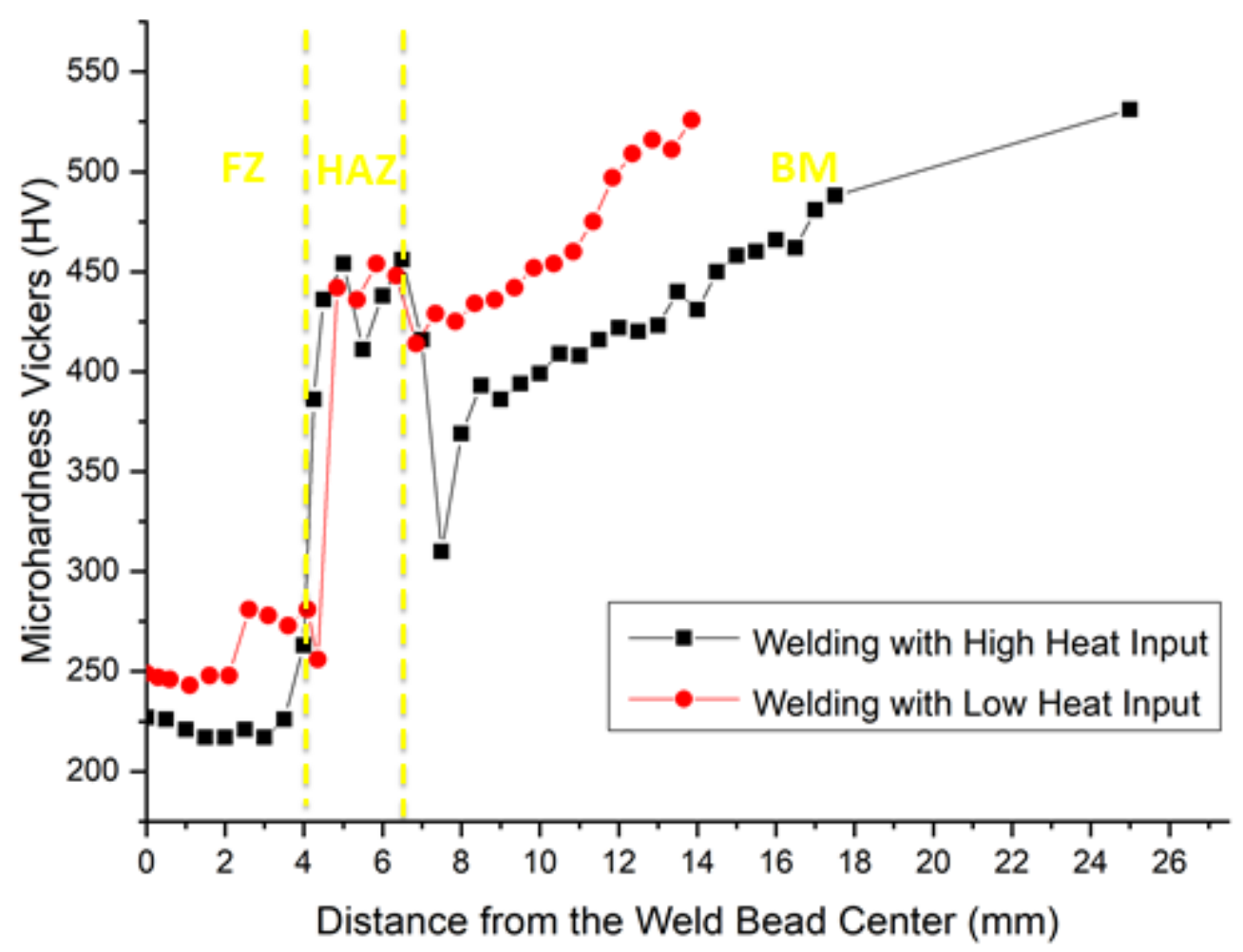

Figure 12. Graphical profile of microhardness measurements along the transversal section of the welded HHA steel for both heat input conditions.

According to the microstructure, Figure 11, and the microhardness profile, Figure 12, it was possible to identify, on both heat input conditions, eight different regions:

- $\quad$ 1st and 2nd region: with low microhardness, associated with the FZ only, where the filler metal is predominant. This region has a ductile microstructure of polygonal ferrite (219-259 HV). However, the grain size resulting from the LHI condition is smaller than that related to the HHI condition in Figures 9a and 10a. Most possibly the increase in heat input contributes to growing the grains. This might be the reason why the $\mathrm{HHI}$ has promoted a decrease in hardness, as reported by Reddy and Mohandas [16] as well as Savic and Cabrilo [25].

- 3rd region: located close to the FZ/HAZ interface with comparatively higher hardness as a result of either coarse or thin martensite (384-275 HV). The coarse martensite was developed due to the HHI condition, Figure $9 b$, while thin martensite can be seen for the LHI condition in Figure 10b. For the HHI microstructure in Figure 9b, it is also possible to identify bainite needles. Generally, a microstructure composed of these bainite needles presents higher toughness [17]. However, due to the small fraction, it did not show much difference in hardness. As for the LHI condition, Figure 10b, bainite needles apparently predominate.

- $\quad 4$ th region in the HAZ, located close to the HAZ/FZ interface, with a sensible increase in hardness (349-430 HV), in which grows the presence of bainite needles within acicular martensite.

- $\quad 5$ th region inside the HAZ with characteristic predominance of bainite needles surrounding lath martensite, Figures $9 \mathrm{~b}$ and $10 \mathrm{~b}$, associated with a plateau of relatively high hardness (375-445 HV).

- 6th region: known as partial transformation zone located at the end of the HAZ, close to the HAZ/BM interface, showing a minor decrease in microhardness due to the presence of ferrite together with martensite, and bainite 424-429 HV);

- 7th region: identified as the BM close to the BM/HAZ interface, discloses a continuous increase in microhardness (437-446 HV) due to the lower temperatures reached in this 
region. It presents the same microstructure as the 6th region but with predominance of tempered martensite as well as lower percentage of bainite and ferrite.

- 8 th region: corresponding to the BM only, with the highest hardness (481-503 HV) associated with tempered martensite with both acicular and lath types, Figure 8.

\subsection{Charpy Impact Energy}

Table 3 presents preliminary Charpy absorbed energy of standard V-notched specimens of the Q\&T HHA BM plate in both longitudinal and transversal to the rolling direction. In this table it is also presented Charpy results of specimens machined from the weldment, transversal to the rolling direction with notch in the HAZ, Figure 2, processed with either HHI or LHI.

Table 3. Charpy absorbed energy.

\begin{tabular}{cc}
\hline Notched Specimen Location & Absorbed Energy (J) \\
\hline Base Metal Longitudinal & $28 \pm 3$ \\
Base Metal Transversal & $29 \pm 2$ \\
Weldment HHI & $53 \pm 3$ \\
Weldment LHI & $69 \pm 2$ \\
\hline
\end{tabular}

The results in Table 3 indicate that practically no difference should exist in absorbed impact energy regarding the direction of the base metal. However, in the weldment, the impact toughness is higher than the base metal, which was also found in a $0.27 \mathrm{C}, 0.64 \mathrm{Cr}$, $1.09 \mathrm{Ni}$, and 0.30 Mo armor steel [34]. Moreover, the result for the weldment with LHI is superior in comparison to HHI, which is attributed to the tougher bainite [17].

\subsection{Tensile Strength}

Tensile properties related to mean values of ultimate stress and toughness, corresponding to maximum strength and area under the stress versus strain curves, respectively, are presented in Table 4 for the BM as well as HHI and LHI welded conditions. Three standard specimens, Figure 3, were tested for each condition in Table 4.

Table 4. Tensile strength and relates toughness of BM, HHI, and LHI welded condition for the Q\&T HHA steel investigated.

\begin{tabular}{cccc}
\hline Tensile Property & BM & HHI & LHI \\
\hline Ultimate Stress $(\mathrm{MPa})$ & $1834 \pm 58$ & $928 \pm 16$ & $992 \pm 60$ \\
\hline Related toughness $\left(10^{3} \mathrm{~kJ} / \mathrm{m}^{3}\right)$ & $117 \pm 4$ & $82 \pm 2$ & $91 \pm 5$ \\
\hline
\end{tabular}

As shown in Table 4, both the tensile strength and related toughness are higher for the BM as compared to both HHI and LHI process conditions. As for the weldment, these properties for the LHI are significantly (within the standard deviation) higher than the HHI. This is coherent with the microhardness results in Table 2 . However, the relatively lower value of the BM Charpy toughness in Table 3 indicates that under dynamic impact the weldment, and particularly the HAZ processed with LHI, has the highest resistance. The ballistic results confirm this performance.

At this point of our discussion, it is worth mentioning that in situations involving dynamic impact, in addition to Charpy and tensile tests, the fracture toughness might also be evaluated by other techniques such as the J-integral measurements, essential work of fracture (EWF) tests and Kahn-type tests [35] as well as finite element model and dynamic drop tests [36]. To our knowledge these techniques have not yet been applied to assess the ballistic performance of welded HHA but mainly to investigate crashworthiness in automotive high strength steels. In particular, Frómeta et al. [35] evaluated the fracture toughness of four advanced high strength steels (AHSS). They 
concluded that EWF technique is the most suitable parameters to describe the global fracture behavior of AHSS sheets. This technique is now included in our ongoing ballistic evaluation of welded HHA.

\subsection{Ballistic Results}

Table 5 presents the results of the $\mathrm{V}_{50}$ ballistic tests in the FZ and HAZ of the welds with low (LHI) and high (HHI) heat input, in addition to results in the BM. It can be noticed in this table that the ballistic limits $\mathrm{V}_{50}$ of the FZ for both HHI, $532 \mathrm{~m} / \mathrm{s}$, and LHI, $556 \mathrm{~m} / \mathrm{s}$, are lower than the corresponding limits of the HAZ, 622 and $668 \mathrm{~m} / \mathrm{s}$, respectively. These results indicate that the HAZ has a significantly higher ballistic resistance than that of the FZ regardless of the heat input. Moreover, welded joints fabricated with LHI have their FZ and HAZ more ballistic resistant than corresponding ones fabricated with HHI. It can also be noted in Table 5 that the FZ for both conditions, HHI and LHI, display ballistic resistance comparable to that of the BM. In fact, the FZ limit velocity for LHI (556 m/s) closely matches that of the BM $(567 \mathrm{~m} / \mathrm{s})$, being only $2 \%$ below.

Table 5. Ballistic results for the investigated HHA weldment regions. ( $\mathrm{P}=$ partial penetration; $\mathrm{T}=$ through perforation).

\begin{tabular}{|c|c|c|c|c|c|c|}
\hline Heat Input & $\begin{array}{l}\text { Shooting } \\
\text { Region }\end{array}$ & \multicolumn{2}{|c|}{$\mathrm{V}_{50}$ Limit Velocity $(\mathrm{m} / \mathrm{s})$} & \multicolumn{3}{|c|}{$E_{i}$ absorbed Impact Energy (kJ) } \\
\hline \multirow{4}{*}{$\begin{array}{c}\text { Without heat } \\
\text { input }\end{array}$} & \multirow{4}{*}{ Base Metal } & $579(\mathrm{~T})$ & $565(\mathrm{P})$ & 1.61 & & 1.53 \\
\hline & & $557(\mathrm{P})$ & $581(\mathrm{~T})$ & 1.49 & & 1.62 \\
\hline & & $552(\mathrm{P})$ & $568(\mathrm{~T})$ & 1.46 & & 1.55 \\
\hline & & \multicolumn{2}{|c|}{$\mathrm{V}_{50}=567$} & \multicolumn{3}{|c|}{$E_{i}=1.54 \pm 0.06$} \\
\hline \multirow{10}{*}{$\begin{array}{l}\text { High heat } \\
\text { input }\end{array}$} & \multirow{4}{*}{$\mathrm{FZ}$} & $529(\mathrm{P})$ & $530(\mathrm{P})$ & 1.34 & 1.38 & 1.35 \\
\hline & & $531(\mathrm{P})$ & $546(\mathrm{~T})$ & 1.35 & 1.39 & 1.43 \\
\hline & & $533(\mathrm{~T})$ & & 1.36 & 1.24 & \\
\hline & & $528(\mathrm{P})$ & & 1.34 & 1.40 & \\
\hline & \multirow{6}{*}{ HAZ } & \multicolumn{2}{|c|}{$\mathrm{V}_{50}=532$} & \multicolumn{3}{|c|}{$\mathrm{E}_{\mathrm{i}}=1.36 \pm 0.05$} \\
\hline & & $607(\mathrm{P})$ & $609(\mathrm{P})$ & 1.77 & & 1.78 \\
\hline & & $611(\mathrm{P})$ & $634(\mathrm{~T})$ & 1.79 & & 1.93 \\
\hline & & $641(\mathrm{~T})$ & $620(\mathrm{P})$ & 1.97 & & 1.85 \\
\hline & & $628(\mathrm{~T})$ & $626(\mathrm{~T})$ & 1.89 & & 1.88 \\
\hline & & & & & $1.85 \pm$ & \\
\hline & & $543(\mathrm{P})$ & $546(\mathrm{P})$ & 1.42 & 1.47 & 1.43 \\
\hline & 57 & $557(\mathrm{~T})$ & $560(\mathrm{~T})$ & 1.49 & 1.44 & 1.51 \\
\hline & 12 & $570(\mathrm{~T})$ & & 1.56 & 1.49 & \\
\hline & & $582(\mathrm{~T})$ & & 1.63 & 1.42 & \\
\hline Low heat & & & & & $1.50 \pm$ & \\
\hline & & $684(\mathrm{~T})$ & $650(\mathrm{P})$ & 2.25 & & 2.03 \\
\hline & HA 7 & $669(\mathrm{~T})$ & $674(\mathrm{~T})$ & 2.15 & & 2.18 \\
\hline & & $663(\mathrm{P})$ & $672(\mathrm{~T})$ & 2.11 & & 2.17 \\
\hline & & $665(\mathrm{P})$ & $667(\mathrm{P})$ & 2.12 & & 2.14 \\
\hline & & & & & $2.14 \pm$ & \\
\hline
\end{tabular}

This improved performance of the FZ may be related to the smaller grain size of the polygonal ferrite, Figure 9a, found with the LHI. On the other hand, the HAZ for both heat inputs display ballistic resistances superior to those of $\mathrm{BM}, 10 \%$ for $\mathrm{HHI}$, and $18 \%$ for 
LHI. Such significant increase in ballistic resistance is possibly related to the formation of bainite that are tougher than tempered martensite. This confirms the prediction that a high toughness is necessary to obtain the best ballistic performance, which was also shown in the Charpy test results in Table 3.

The higher $\mathrm{V}_{50}$ of HAZ for LHI condition in Table 5 was probably obtained due to a favorable combination of hardness from the finer grain size of martensite plates in association with the toughness of bainite needles. Another parameter that corroborates the ballistic limit results is the absorbed impact energy $\left(\mathrm{E}_{\mathrm{i}}\right)$ presented in Table 5. It is worth noticing that for $\mathrm{HHI}$, the values of $\mathrm{E}_{\mathrm{i}}=1.36 \mathrm{~kJ}$ in the $\mathrm{FZ}$ and $1.85 \mathrm{~kJ}$ in the $\mathrm{HAZ}$ are significantly lower than those corresponding to $1.50 \mathrm{~kJ}$ in the FZ and $2.14 \mathrm{~kJ}$ in the HAZ for LHI. Moreover, the BM also displays a mean $\mathrm{E}_{\mathrm{i}}, 1.54 \mathrm{~kJ}$, significantly lower than that of HAZ associated with LHI. These $E_{i}$ results also confirm the superior ballistic performance of the HAZ in the Q\&T HHA steel welded with LHI and are supported by the microstructure results in Figure 10b. Indeed, an explanation for this superior ballistic behavior of the HAZ in welded joints fabricated with LHI is based on its microstructure.

Another point worth mentioning is that few weldments were fabricated with reversed direction regarding the two top weld beads, as illustrated in Figure 1c. The intention was to verity the influence of this procedure on the ballistic results. These few reversed welding direction experiments, within the standard deviation of all microhardness, limit velocity and absorbed impact energy, failed to show any significance difference to corresponding results of one-direction welding.

Despite the lower hardness, as compared to BM in Table 2, the HAZ of a welded Q\&T HHA steel has quantitatively shown, for the first time by means of standard $V_{50}$, to be the region with highest ballistic resistance. This is attributed to a combination of both hardness, provided by martensite, and toughness, by the bainite. Therefore, hardness is not the main factor in the steel ballistic resistance. Furthermore, the so-called soft region, associated with the FZ of the Q\&T HHA steel welded joint, has a ballistic resistance comparable to that of the $\mathrm{BM}$, as long as the welding process is conducted with heating input equal to or below $0.8 \mathrm{~kJ} / \mathrm{mm}[16]$.

\subsection{Ballistic Damage Mode}

After ballistic test, it is required by the standard [26] to visually analyze the damage caused by the projectile impact. In principle, this damage could be ductile in association with a perforation hole with diameter close to that of the projectile and intense plastic deformation without fragmentation, or else a brittle damage with a relatively larger diameter and evidence of fragmentation due to the material's hardness.

Figure 13 shows the ballistic damage in the zones of the HHI processed weldment subjected to projectile velocity higher than $\mathrm{V}_{50}$. In this figure frontal damage at the $\mathrm{FZ \text {, }}$ Figure 13a, HAZ, Figure $13 \mathrm{c}$ and BM, Figure 13e, reveal a plugging penetration with diameter close to that of projectile and occurrence of scabbing. In addition, the corresponding distal faces, Figure $13 \mathrm{~b}, \mathrm{~d}, \mathrm{f}$ disclose signs of fragmentation and petaling, indicating a combination of ductile and brittle damage.

Figure 14 shows the ballistic damage in the LHI weldment after projectile impact with velocity higher than $\mathrm{V}_{50}$. Similar damage modes to HHI weldment (Figure 13) are observed in this figure. In particular, a marked degree of fragmentation in the distal faces, Figure $14 \mathrm{~b}, \mathrm{~d}$, f might be associated with predominant brittle mode, which correlates with the higher hardness, Table 2, and impact toughness, Table 3, of LHI.

Microhardness results presented in Table 2 together with microstructure observations in Figures 9 and 10, as well as ballistic limit velocity and absorbed impact energy in Table 5, confirm the superior ballistic performance of welded joints processed with LHI. 

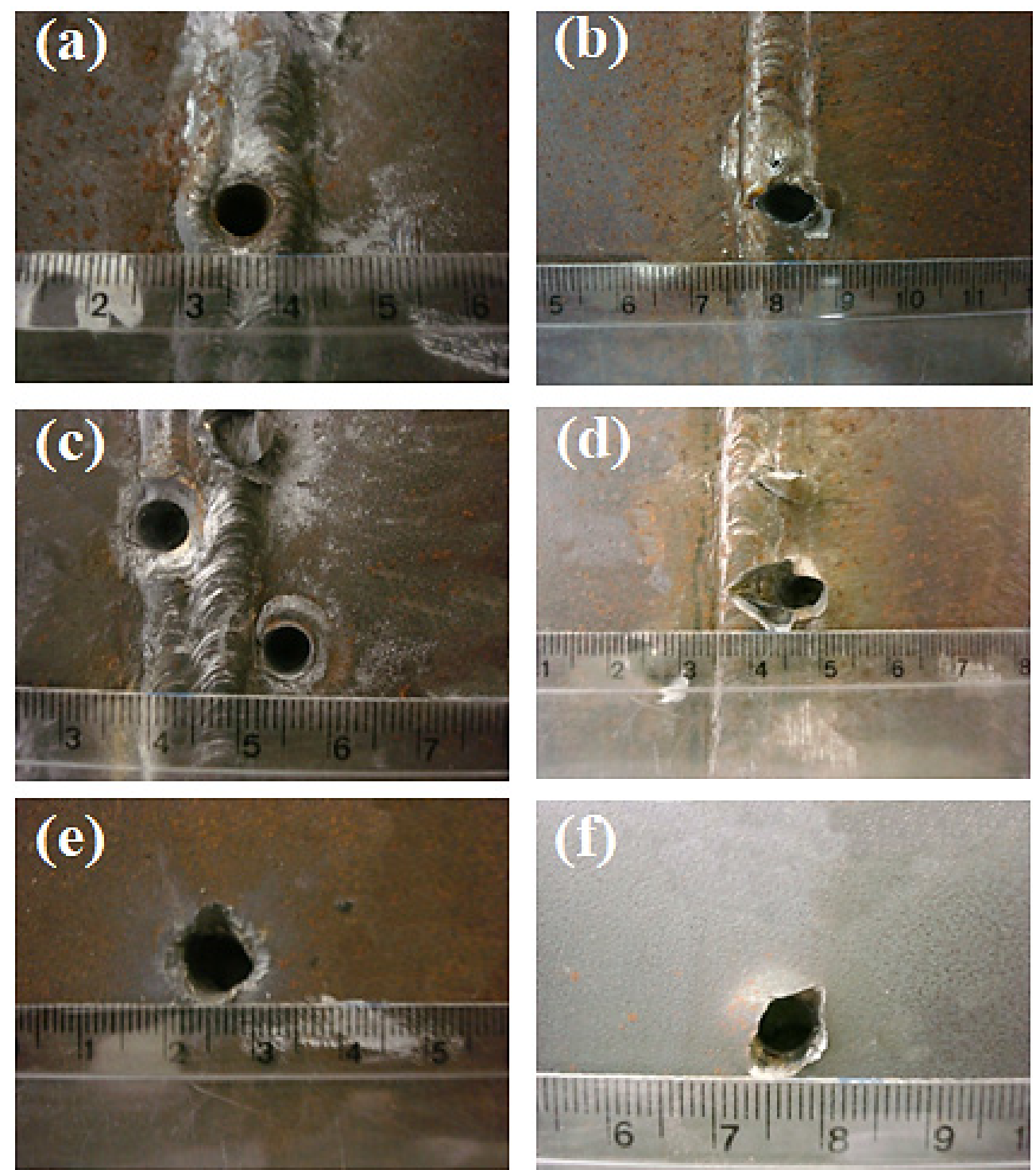

Figure 13. Ballistic damage at $\mathrm{HHI}$ weldment from 7.62 projectile impact with velocity higher than $\mathrm{V}_{50}$ : (a) frontal hole in FZ; (b) distal hole in FZ; (c) frontal hole in HAZ; (d) distal hole in HAZ; (e) frontal hole in BM; and (f) distal hole in BM. (Ruler small divisions in mm). 

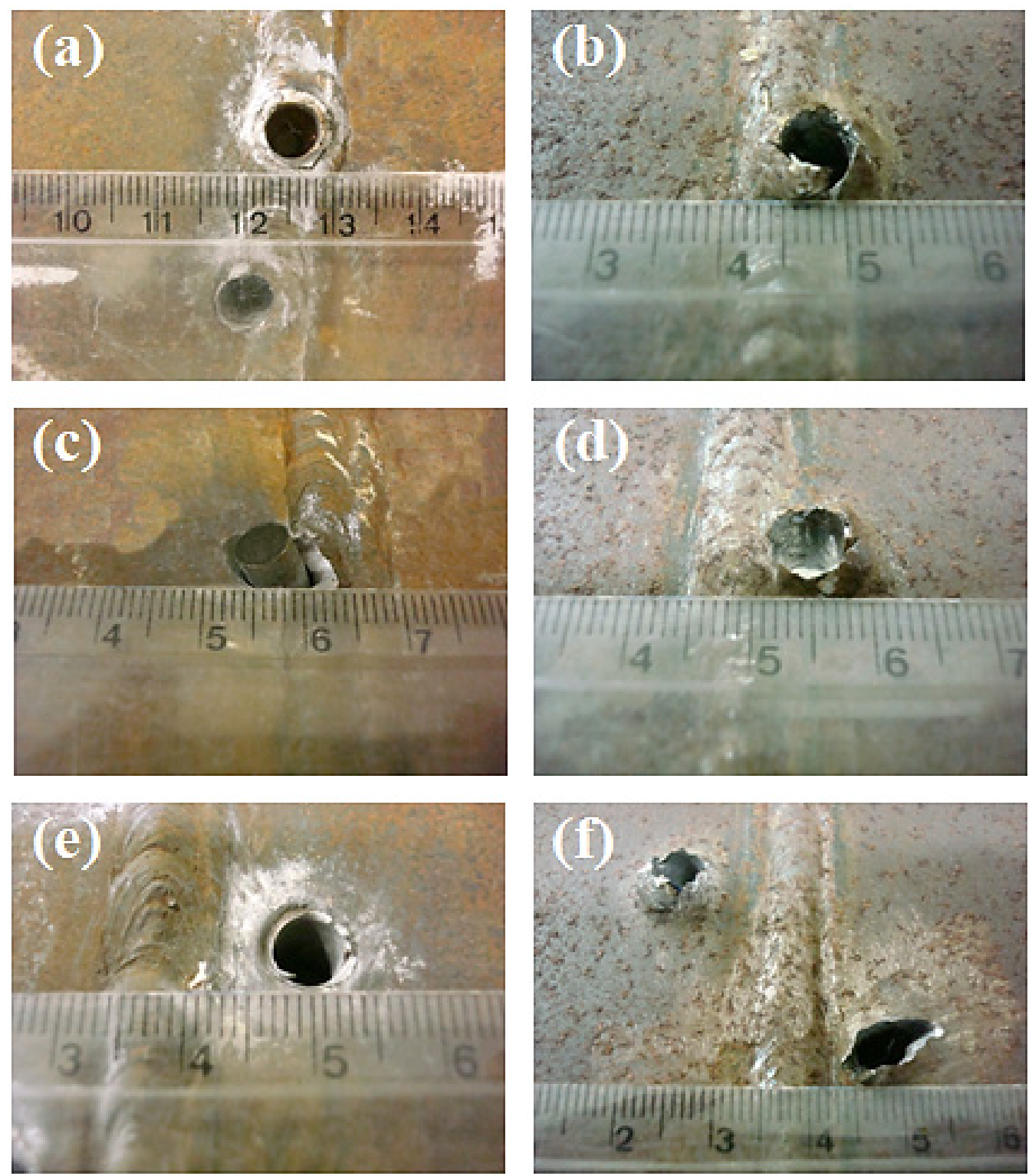

Figure 14. Ballistic damage at LHI weldment from $7.62 \mathrm{~mm}$ projectile impact with velocity higher than $\mathrm{V}_{50}$ : (a) frontal hole in FZ; (b) distal hole in FZ; (c) frontal hole in HAZ; (d) distal hole in HAZ; (e) frontal hole in BM; and (f) distal hole in BM. (Ruler small divisions in $\mathrm{mm}$ ).

\section{Conclusions}

- The ballistic limit performance of the welded joint of a quenched and tempered (Q\&T) high strength armor (HHA) steel was for the first time evaluated by the $\mathrm{V}_{50}$ standard method using high impact velocity $7.62 \mathrm{~mm}$ caliber ammunition.

- Based on two welding heat inputs; lower, $0.8 \mathrm{~kJ} / \mathrm{mm}$ (LHI) and higher, $1.2 \mathrm{~kJ} / \mathrm{mm}$ (HHI), selected from the literature, the effect of heat input on the hardness, considered a major ballistic requirement, was disclosed together with $V_{50}$ for the Q\&T HHA steel welded joint region.

- Quantitative results of microhardness and $\mathrm{V}_{50}$ limit velocity for the fusion zone (FZ), heat-affected zone (HAZ) and base metal (BM) revealed that, in spite of BM being the hardest region with $503 \mathrm{HV}$, the HAZ is ballistically the most resistant, with $\mathrm{V}_{50}=668 \mathrm{~m} / \mathrm{s}$, associated with LHI.

- The unexpected finding that HAZ with lower hardness might be more ballistic resistant than BM is now revealed in terms of developed microstructure after the LHI welding procedure. While the BM owns its higher hardness to Q\&T martensite, 
unaffected by the welding temperature, the HAZ displays a $\mathrm{V}_{50}$ ballistic tougher microstructure due to predominant formation of bainite, which causes a superior ballistic performance.

- Ballistic damage modes of HHI and LHI weldments disclosed evidence of plugging, petaling, and fragmentation associated with a combination of ductile and brittle projectile perforation. A market degree of fragmentation in the LHI distal face of FZ, HAZ, and BM indicates predominant brittle mode, which correlates with measured higher hardness and impact toughness.

Author Contributions: Conceptualization R.P.W.; methodology, S.N.M. and R.P.W.; formal analysis, E.R.S.S.; investigation, E.R.S.S.; writing—original draft preparation, E.R.S.S. and R.P.W.; writingreview and editing, S.N.M. and S.d.S.O.; supervision, R.P.W. All authors have read and agreed to the published version of the manuscript.

Funding: This research received no external funding.

Institutional Review Board Statement: Not applicable.

Informed Consent Statement: Not applicable.

Data Availability Statement: The data presented in this study are available upon request to the corresponding author.

Acknowledgments: The authors thank the Brazilian Army and the national financial agencies (CNPq, CAPES, and FAPERJ) for sponsoring this research. This paper is dedicated in memoriam to João Carlos Miguez Suarez, one of the founders of our laboratory of Ballistic Tests at the Military Institute of Engineering, who has recently passed away.

Conflicts of Interest: The authors declare no conflict of interest.

\section{References}

1. Jena, P.; Mishra, B.; RameshBabu, M.; Babu, A.; Singh, A.; SivaKumar, K.; Bhat, T.B. Effect of heat treatment on mechanical and ballistic properties of a high strength armour steel. Int. J. Impact Eng. 2010, 37, 242-249. [CrossRef]

2. Vasconcelos, C.H.M.; Loayza, C.R.L.; Assunção, P.D.C.; Junior, F.F.B.; Baia, P.E.C.; Borges, D.J.A.; Braga, E.M. High-hardness armor welded by CW-GMAW: Economic, geometric and CGHAZ analysis. J. Braz. Soc. Mech. Sci. Eng. 2019, 41, 268. [CrossRef]

3. Jo, M.C.; Kim, S.; Suh, D.W.; Hong, S.S.; Kim, H.K.; Sohn, S.S.; Lee, S. Effect of tempering conditions on adiabatic shear banding during dynamic compression and ballistic impact tests of ultra-high-strength armor steel. Mater. Sci. Eng. A 2020, 792, 139818. [CrossRef]

4. Popławski, A.; Kędzierski, P.; Morka, A. Identification of Armox 500T steel failure properties in the modeling of perforation problems. Mater. Des. 2020, 190, 108536. [CrossRef]

5. Magudeeswaran, G.; Balasubramanian, V.; Reddy, G.M. Metallurgical characteristics of armour steel welded joints used for combat vehicle construction. Def. Technol. 2018, 14, 590-606. [CrossRef]

6. Yurianto, Y.; Pratikto, P.; Soenoko, R.; Suprapto, W. Effect of quench and temper on hardness and wear of HRP steel (armor steel candidate). Eastern-Eur. J. Enterp. Technol. 2019, 3, 55-61. (In Russian) [CrossRef]

7. Ma, B.-H.; Ma, D.-F.; Wang, H.-R.; Chen, D.-N.; Zhou, F.-H. Ballistic impact response of resistance-spot-welded (RSW) doublelayered plates for Q\&P980 steel. Def. Technol. 2021. [CrossRef]

8. Oliveira, S.D.S.; Weber, R.P.; Paula, A.D.S.; Monteiro, S.N. The Influence of the Microstructure of an HHA Steel on the Formation of Adiabatic Shear Bands, after High Deformation Rates. Mater. Sci. Forum 2020, 1012, 366-371. [CrossRef]

9. Saxena, A.; Kumaraswamy, A.; Dwivedi, S.P.; Srivastava, A.K.; Maurya, N.K. Experimental and computational investigation on dynamic fracture toughness (J) behavior of multi-pass SMA armor steel weldments. Theor. Appl. Fract. Mech. 2020, 106, 102502. [CrossRef]

10. Fan, X.; Li, Y.; Qi, Y.; Cai, X.; Wang, Z.; Ma, C. Mechanical properties of cryogenic high manganese steel joints filled with nickel-based materials by SMAW and SAW. Mater. Lett. 2021, 304, 130596. [CrossRef]

11. Cabrilo, A.; Geric, K. Weldability of High Hardness Armor Steel. Adv. Mater. Res. 2016, 1138, 79-84. [CrossRef]

12. Cabrilo, A.; Sedmak, A.; Burzic, Z.; Perkovic, S. Fracture mechanics and fatigue crack propagation in armor steel welds. Eng. Fail. Anal. 2019, 106, 104155. [CrossRef]

13. Bunaziv, I.; Wenner, S.; Ren, X.; Frostevarg, J.; Kaplan, A.F.; Akselsen, O.M. Filler metal distribution and processing stability in laser-arc hybrid welding of thick HSLA steel. J. Manuf. Process. 2020, 54, 228-239. [CrossRef]

14. Wilson, I. The Development of Welding Techniques for British Fighting Vehicles; Crown Copyright: London, UK, $1987 ;$ pp. 47-55.

15. Ade, F. Ballistic qualification of armour steel weldments. Weld. J. 1991, 70, 53-54. 
16. Reddy, G.M.; Mohandas, T. Ballistic performance of high-strengh low-alloy steel weldments. J. Mater. Process. Technol. 1996, 57, 23-30. [CrossRef]

17. Crouch, I.G. Metallic armour, from cast aluminium alloys to high strength steels. Mater. Forum 1988, 12, 31-37.

18. Ramana, P.V.; Reddy, G.M.; Mohandas, T. Residual stress distribution in high strength low alloy steel weldments. Ind. J. Non Dest. Test Eval. 2007, 6, 33-40.

19. Pramanick, A.; Das, H.; Reddy, G.; Ghosh, M.; Das, G.; Nandy, S.; Pal, T. Development and design of microstructure based coated electrode for ballistic performance of shielded metal arc welded armour steel joints. Mater. Des. 2016, 103, 52-62. [CrossRef]

20. Reddy, G.M.; Mohandas, T.; Papukutty, K. Effect of welding process on the ballistic performance of high-strength low-alloy steel weldments. J. Mater. Process. Technol. 1998, 74, 27-35. [CrossRef]

21. Reddy, G.M.; Mohandas, T.; Sarma, D.S. Cold cracking studies on low alloy steel weldments: Effect of filler metal composition. Sci. Technol. Weld. Join. 2003, 8, 407-414. [CrossRef]

22. Saxena, A.; Kumaraswamy, A.; Reddy, G.M.; Madhu, V. Influence of welding consumables on tensile and impact properties of multi-pass SMAW Armox 500T steel joints vis-a-vis base metal. Def. Technol. 2018, 14, 188-195. [CrossRef]

23. Balakrishnan, M.; Balasubramanian, V.; Reddy, G.M. Effect of joint design on ballistic performance of quenched and tempered steel welded joints. Mater. Des. 2014, 54, 616-623. [CrossRef]

24. Balakrishnan, M.; Balasubramanian, V.; Reddy, G.M.; Sivakumar, K. Effect of buttering and hardfacing on ballistic performance of shielded metal arc welded armour steel joints. Mater. Des. 2011, 32, 469-479. [CrossRef]

25. Savic, B.; Cabrilo, A. Effect of Heat Input on the Ballistic Performance of Armor Steel Weldments. Materials 2021, $14,3617$. [CrossRef]

26. US Army. MIL-DTL-46100E (MR). Amendment 1. Detail Specification. Armor Plate, Steel, Wrought, High-Hardness. 2008. Available online: http:/ / everyspec.com/MIL-SPECS/MIL-SPECS-MIL-DTL/MIL-DTL-46100E_AMENDMENT-1_20496/ (accessed on 7 September 2021).

27. US Army. MIL-STD-662F Department of Defense. 1997. Available online: http:/ / everyspec.com/MIL-STD/MIL-STD-0500-069 9/MIL-STD-662F_6718/ (accessed on 7 September 2021).

28. American Society for Testing and Materials. Standard Test Method for Knoop and Vickers Hardness of Materials, ASTM E384-11. 2011. Available online: https://compass.astm.org/document/?contentCode=ASTM\%7CE0384-11\%7Cen-US (accessed on 6 September 2021).

29. American Society for Testing and Materials. Standard Test Methods for Notched Bar Impact Testing of Metallic Materials, ASTM, E23-1a. 2002. Available online: https:/ / compass.astm.org/document/?contentCode=ASTM\%7CE0023-01A\%7Cen-US (accessed on 7 September 2021).

30. American Society for Testing and Materials. Standard Test Methods and Definitions for Mechanical Testing of Steel Products, ASTM A370-14. 2014. Available online: https:// compass.astm.org/document/?contentCode=ASTM\%7CA0370-14\%7Cen-US (accessed on 7 September 2021).

31. United States Department of the Army. Test Operations Procedure 2-2-710. Ballistic Tests of Armor Materials. 1984. Available online: https: / / www.document-center.com/standards/show/TOP-2-2-710 (accessed on 7 September 2021).

32. Oliveira, M.S.; da Luz, F.S.; Lopera, H.A.C.; Nascimento, L.F.C.; Filho, F.D.C.G.; Monteiro, S.N. Energy Absorption and Limit Velocity of Epoxy Composites Incorporated with Fique Fabric as Ballistic Armor-A Brief Report. Polymers 2021, $13,2727$. [CrossRef]

33. Unfried, J.S.; Garzon, C.M.; Giraldo, J.E. Numerical and experimental analysis of microstructure evolution during arc welding in armor plate steels. J. Mater. Process. Technol. 2009, 209, 1688-1700. [CrossRef]

34. Cabrilo, A.; Geric, K. Fracture mechanic and charpy impact properties of a crack in weld metal, HAZ and base metal of welded armor steel. Procedia Struct. Integr. 2018, 13, 2059-2064. [CrossRef]

35. Frómeta, D.; Parareda, S.; Lara, A.; Molas, S.; Casellas, D.; Jonsén, P.; Calvo, J. Identification of fracture toughness parameters to understand the fracture resistance of advanced high strength sheet steels. Eng. Fract. Mech. 2020, 229, 106949. [CrossRef]

36. Li, Q.Q.; Li, E.; Chen, T.; Wu, L.; Wang, G.; He, Z. Improve the frontal crashworthiness of vehicle through the design of front rail. Thin-Walled Struct. 2021, 162, 107588. [CrossRef] 